\title{
Pengaruh Tuned Mass Damper (TMD) Terhadap Respons Getaran pada Struktur Bangunan
}

(Effect of Tuned Mass Damper (TMD) on Vibration Response for Building Structure Model)

\author{
DEDI SURYADI, M. RASYID RIDLO, NOVALIO DARATHA, INDRA AGUSTIAN
}

\begin{abstract}
ABSTRAK
Penelitian ini didasari oleh banyaknya kehancuran struktur bangunan yang terjadi akibat gempa bumi, sehingga dibutuhkan suatu sistem peredam yang efektif sebagai solusi untuk struktur bangunan. Penelitian ini menganalisis pengaruh penambahan Tuned Mass Damper (TMD) pada struktur bangunan berlantai satu. Penelitian ini dilakukan pengujian secara eksperimental dengan cara membandingkan respons getaran struktur tanpa TMD dan dengan penambahan TMD. Nilai rasio massa dan kekakuan yang gunakan masing-masing adalah dari $2 \%$ sampai $20 \%$ dari nilai parameter struktur utama dengan variasi kenaikan $2 \%$ untuk setiap langkah. Rasio massa didefinisikan sebagai perbandingan massa struktur dengan massa damper, sedangkan rasio kekakuan adalah perbandingan antara kekakuan struktur dan kekakuan damper. Frekuensi gaya gangguan adalah sebesar 10,5 rad/s, $11 \mathrm{rad} / \mathrm{s}$, dan 11,5 rad/s. Hasil penelitian ini menunjukkan bahwa penambahan TMD pada struktur dengan rasio TMD yang tepat cukup efektif dalam mengurangi respons amplitudo pada struktur. Nilai rasio TMD dengan md 12\% dan kd 10\% untuk frekuensi gaya gangguan 11,5 rad/s memperlihatkan hasil reduksi amplitudo struktur sebesar 75,19\% dibandingkan dengan amplitudo struktur tanpa TMD.
\end{abstract}

Kata kunci: Amplitudo, Rasio Massa, Rasio Kekakuan, Struktur, Tuned Mass Damper (TMD)

\section{ABSTRACT}

This research background was based on destruction of the structures caused by the earthquake. Thus, an effective damper system was needed for a solution of building structures. Here, effects of Tuned Mass Damper (TMD) on one-storey structure were considered. This research was experimentally demonstrated by comparing the vibration response of structures between structures without TMD and those with TMD. Mass and stiffness ratios were varied from $2 \%$ to $20 \%$ with increment by $2 \%$ each step, respectively. Mass ratio and stiffness ratio were defined as mass of structure divided by one of dampers and stiffness of structure divided by one of dampers, respectively. Moreover, disturbance force frequency on structure was varied of $10.5 \mathrm{rad} / \mathrm{s}, 11 \mathrm{rad} / \mathrm{s}$, and $11.5 \mathrm{rad} / \mathrm{s}$. The results showed that the addition of TMD on the structure with appropriate TMD ratio was quite effective in reducing the amplitude response of the structure. The amplitude of structure is reduced by $75.19 \%$ when structure was added with TMD at mass ratio of $12 \%$ and stiffness ratio of $10 \%$ for force frequency of $11.5 \mathrm{rad} / \mathrm{s}$.

Keywords: Amplitude, Mass Ratio, Stiffness Ratio, Structure, Tuned Mass Damper $(T M D)$ 


\section{PENDAHULUAN}

Gempa bumi seringkali menyebabkan dampak buruk, terutama pada struktur bangunan. Hal ini menyebabkan kekhawatiran terkait dengan keamanan struktur dan kenyamanan penghuninya (Liu et. al, 2020). Untuk mendapatkan bangunan yang nyaman dibutuhkan persyaratan keselamatan dan operasi dengan menyesuaikan kekuatan struktur, akibatnya desain yang dihasilkan seringkali tidak ekonomis dan cenderung sulit untuk dibangun (Hart dkk, 2012).

Berbagai upaya dilakukan untuk mengkaji struktur yang mampu menahan gaya gangguan, baik beban gempa maupun beban angin. Penggunaan damper jenis steel damper bearing pada struktur dapat mereduksi beban arah vertikal dan horizontal (Liu dkk, 2018). Penambahan Pipe Fuse Damper (PFD) pada struktur yang merupakan peredam logam pasif dapat berfungsi untuk meningkatkan respons seismik struktur dengan disipasi energi gempa yang besar (Aghlara dkk, 2018). Akan tetapi dari penelitian-penelitian tersebut masih banyak hal yang harus dievaluasi dan dikembangkan, karena penerapannya lebih cenderung pada rekonstruksi bangunan baru.

Untuk meningkatkan kinerja struktur dalam menerima gaya gangguan dapat dicapai dengan cara memanipulasi amplitudo dan frekuensi getaran struktur dengan memodifikasi massa struktur, kekakuan, bentuk dan redaman (Mendis dkk, 2007). Selain itu, penambahan gaya stabilisasi pasif atau aktif pada struktur juga dapat diterapkan untuk mengurangi efek dari getaran struktural (Gerges \& Vickery, 2005). Penambahan Tuned Mass Damper (TMD) diakui dapat menjadi alternatif untuk menyelamatkan struktur yang sudah ada, maupun struktur yang akan dibuat dengan biaya yang lebih ekonomis (Hebbar dkk, 2019).

TMD dapat mengubah karakteristik dinamis struktur utama dan mentransfer gaya gangguan yang dialami struktur utama menuju TMD (Chang dkk, 2019). Kontrol pasif pada TMD memanfaatkan energi potensial yang dibangkitkan oleh respon struktur untuk menghasilkan gaya kontrol (Tjong dkk, 2004). TMD telah berhasil diimplementasikan di gedung gedung tinggi yang ada, seperti Taipei 101 di Taiwan, Citicorp Center di New York,
John Hancock Center di Boston, Menara CN di Toronto, dan Menara Sydney di Sydney. Selain itu, sejumlah menara observasi di Jepang juga dipasang TMD. Hasilnya menunjukkan bahwa penambahan TMD dapat secara signifikan mengurangi respons getaran gedung-gedung tinggi di bawah pengaruh gempa bumi dan angin. (Kareem dkk, 1999). Penelitian tentang pengembangan prosedur perancangan Tuned Mass Damper berdasarkan kontrol algoritma aktif, yaitu kendali $\mathrm{H}_{2}$ / LQG menyederhanakan persamaan kontrol umpan balik dalam algoritma kontrol aktif untuk menentukan pegas dan peredam pada TMD (Chang dkk, 2018). Penelitian mengenai efisiensi TMD untuk mitigasi efek seismik pada bangunan dengan memperhatikan interaksi struktur tanah telah dilakukan. Hasil studi menunjukkan bahwa baik interaksi struktur tanah maupun aplikasi TMD cenderung mengurangi osilasi struktur, namun kontribusi relatifnya bergantung pada kekakuan relatif antara struktur dan pondasi tanah. Dengan demikian, kurva kinerja TMD ditentukan berdasarkan efisiensi TMD dengan kekakuan relatif struktur ke tanah (Gorini \& Chisari, 2019).

Pemodelan sistem peredam (Tuned Mass Damper) pada struktur menggunakan matlab simulink pernah menjadi topik penelitian untuk memperoleh grafik respons dinamis struktur 2 lantai tanpa TMD dan menggunakan TMD dengan memvariasikan nilai rasio TMD terhadap parameter struktur utama (Suryadi dkk, 2019). Untuk posisi TMD itu sendiri, berada pada posisi atas dari struktur, berdasarkan penelitian analisis efektivitas penempatan posisi TMD pada struktur (Sikumbang, 2014).

Sistem peredam TMD ini diharapkan dapat menjadi solusi untuk mengatasi kegagalan struktur, terutama struktur berlantai satu di zona rawan gempa. Maka dari itu, pada penelitian ini bertujuan untuk mengkaji pengaruh respons getaran pada model struktur tanpa TMD dan dengan penambahan TMD secara eksperimental. Pengujian ini diaplikasikan pada struktur satu lantai agar menjadi solusi bagi masyarakat menengah ke bawah dikarenakan biaya yang lebih ekonomis. Nilai massa dan kekakuan TMD divariasikan agar dapat menghasilkan grafik fenomena struktur tanpa TMD dan struktur menggunakan TMD. Pengamatan dari fenomena grafik hasil pada penelitian ini akan 
menjadi pedoman seberapa efektif desain TMD dalam mereduksi gaya gangguan pada struktur.

\section{METODE PENELITIAN}

Penelitian ini dilakukan untuk mengetahui respons dinamis dari struktur satu lantai tanpa TMD dan dengan penambahan TMD. Dalam proses analisis dilakukan beberapa langkah.

\section{Perhitungan Variabel Struktur}

Perhitungan nilai variabel struktur dilakukan untuk mendapatkan nilai massa dan kekakuan dari struktur tersebut. Selain itu nilai massa dan kekakuan struktur digunakan untuk menentukan nilai rasio dari TMD yang akan digunakan. Tipe konfigurasi struktur yang dijadikan objek pembahasan yaitu struktur bangunan 1 lantai yang dapat dilihat pada Gambar 1.

Berdasarkan Gambar 1 diperoleh nilai massa struktur sebesar $0,8 \mathrm{~kg}$ dan kekakuan struktur sebesar $389,76 \mathrm{~N} / \mathrm{m}$.

\section{Perhitungan Nilai Variabel Struktur}

Berdasarkan nilai dari massa dan kekakuan struktur di atas, maka didapatkan nilai rasio massa dan kekakuan TMD yang dapat dilihat pada Tabel 1.

\section{Perancangan Alat Ukur Percepatan}

Proses pengujian pengukuran respons getaran ini menggunakan bantuan sensor accelerometer ADXL335 dengan prinsip kapasitor untuk mendeteksi percepatan pada massa di dalamnya dan mampu mengukur 3 arah $(\mathrm{X}, \mathrm{Y}, \mathrm{Z})$ getaran sekaligus. Akan tetapi dalam penelitian ini hanya membahas getaran arah $\mathrm{Z}$. Wiring diagram dari perancangan alat ukur ini dapat dilihat pada Gambar 2.

\section{Prosedur Pengujian}

Pengujian ini dilakukan dengan membandingkan respons simpangan struktur tanpa TMD dan dengan penambahan TMD. Nilai rasio TMD yang gunakan adalah antara 2-20\% dari nilai parameter struktur utama dengan variasi kenaikan $2 \%$. Alur pengujian dapat dilihat pada Gambar 3.

Struktur akan diberi frekuensi gaya gangguan dari meja getar sebesar 10,5 rad/s, $11 \mathrm{rad} / \mathrm{s}$, $11,5 \mathrm{rad} / \mathrm{s}$ selama 20 detik. Respons percepatan diukur dengan menggunakan alat ukur percepatan yang diposisikan di atas dan di tumpuan struktur seperti pada Gambar 3. Respons percepatan disajikan menggunakan serial monitor pada laptop dan disimpan dalam bentuk data tabel Ms. Excel yang kemudian akan dikonversi menjadi respons simpangan dengan menggunakan Persamaaan 1.

$$
\mathrm{x}=\frac{\ddot{\mathrm{x}}}{\omega^{2}}
$$

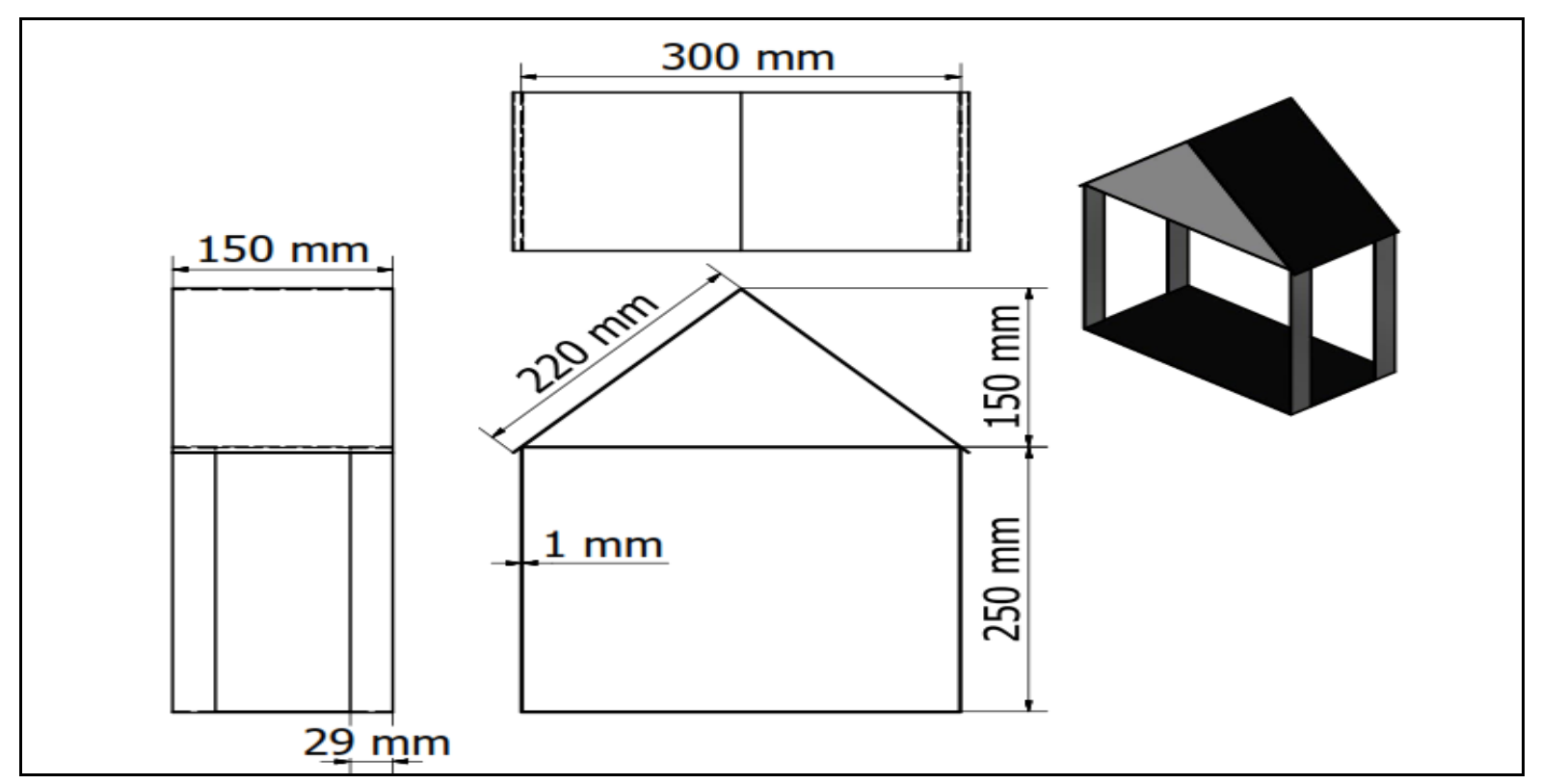

GAMBAR 1. Konfigurasi Struktur 1 Lantai 
TABEL 1. Nilai Rasio TMD

\begin{tabular}{ccc}
\hline Rasio & Massa TMD $(\mathbf{k g})$ & Kekakuan TMD $(\mathbf{N} / \mathbf{m})$ \\
\hline $2 \%$ & 0,016 & 7,7952 \\
$4 \%$ & 0,032 & 15,5904 \\
$6 \%$ & 0,048 & 23,3856 \\
$8 \%$ & 0,064 & 31,1808 \\
$10 \%$ & 0,08 & 38,976 \\
$12 \%$ & 0,096 & 46,7712 \\
$14 \%$ & 0,112 & 54,5664 \\
$16 \%$ & 0,128 & 62,3616 \\
$18 \%$ & 0,144 & 70,1568 \\
$20 \%$ & 0,16 & 77,952 \\
\hline
\end{tabular}

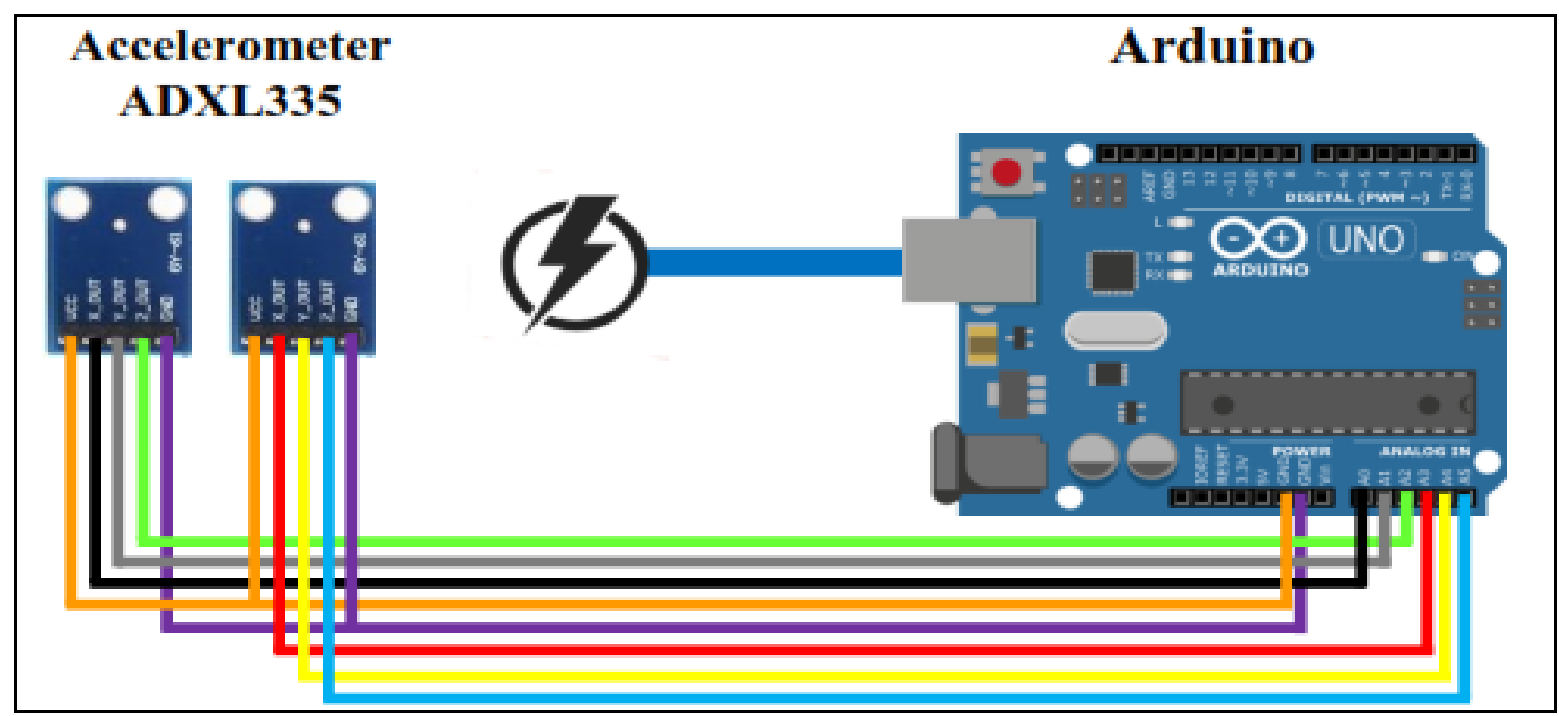

GAMBAR 2. Wiring Diagram Alat Ukur Percepatan

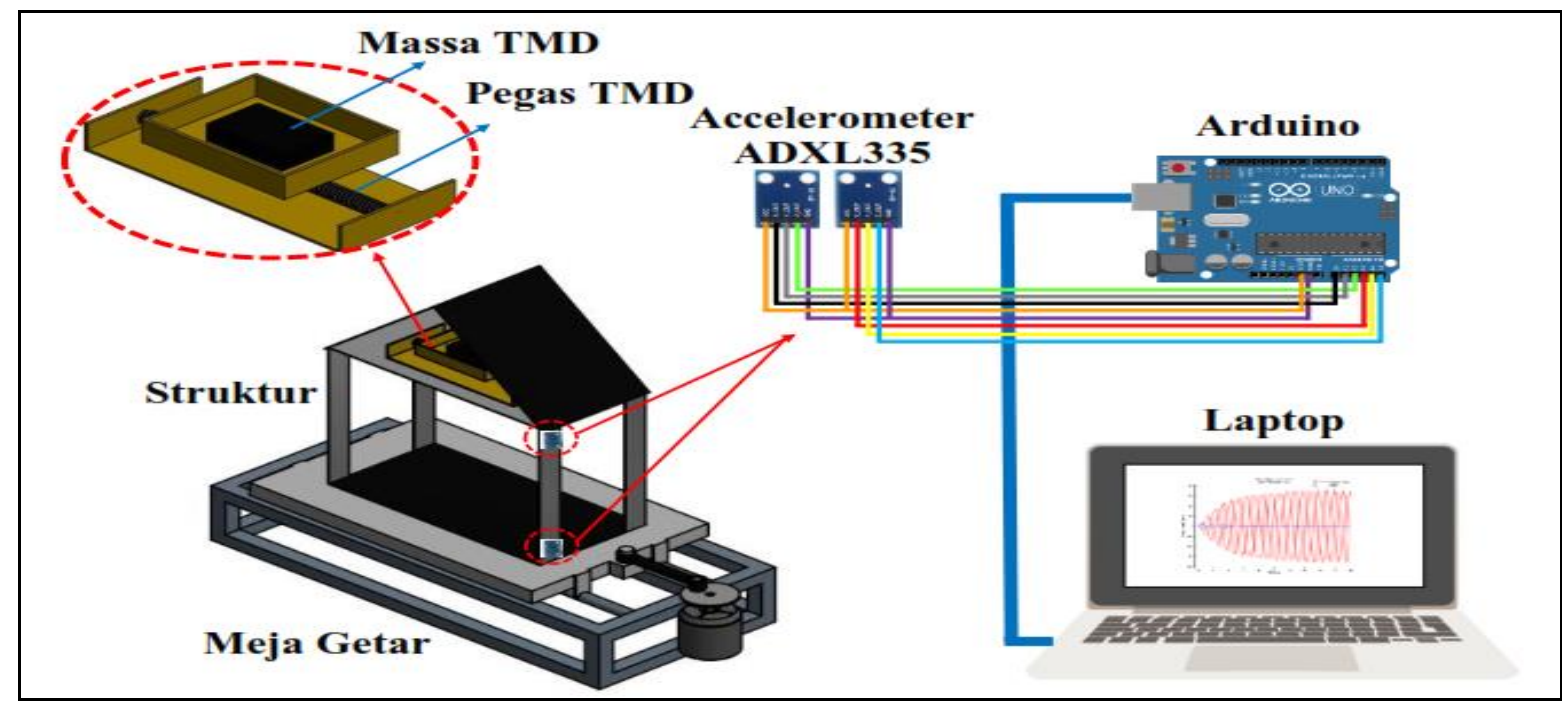

GAMBAR 3. Skema Pengujian Alat 


\section{HASIL DAN PEMBAHASAN}

Penambahan TMD pada struktur bertujuan untuk mereduksi respons simpangan pada struktur agar dapat meminimalisir kerusakan yang terjadi. Hasil penelitian ini berupa grafik respons simpangan struktur tanpa TMD dan dengan penambahan TMD. Respons tersebut diakibatkan karena gaya gangguan yang diberikan pada landasan struktur. Grafik respons struktur tanpa TMD dengan frekuensi gaya gangguan sebesar $11.5 \mathrm{rad} / \mathrm{s}$ selama $20 \mathrm{~s}$ dapat dilihat pada Gambar 4. Nilai amplitudo yang didapatkan pada respons simpangan struktur tanpa TMD yaitu $0,04928 \mathrm{~m}$ dan struktur berhenti berosilasi setelah mengalami peluruhan pada $54,8 \mathrm{~s}$. Hal ini menunjukkan bahwa penggunaan TMD dapat mereduksi getaran yang terjadi pada struktur akibat gaya gangguan (Mendis dkk, 2007).

Perbandingan respons simpangan struktur tanpa TMD dan dengan penambahan TMD dengan rasio md $12 \%$ dan $\mathrm{kd} 10 \%$ dengan gaya gangguan $11,5 \mathrm{rad} / \mathrm{s}$ dapat dilihat pada Gambar 5. Hasil pengujian ini selaras dengan dengan hasil kaji teoritik (Suryadi dkk, 2019).

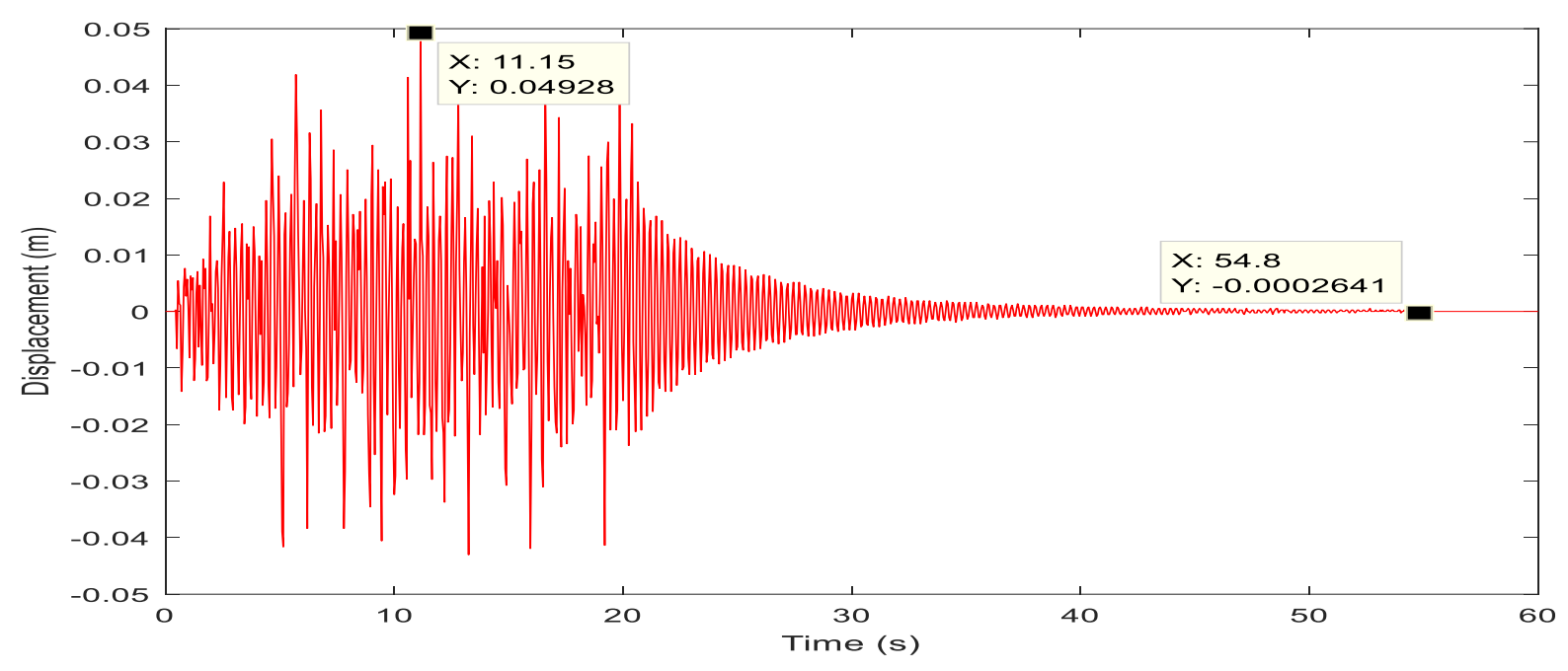

GAMBAR 4. Grafik Respons Struktur Tanpa TMD Dengan Gaya Gangguan $11.5 \mathrm{rad} / \mathrm{s}$

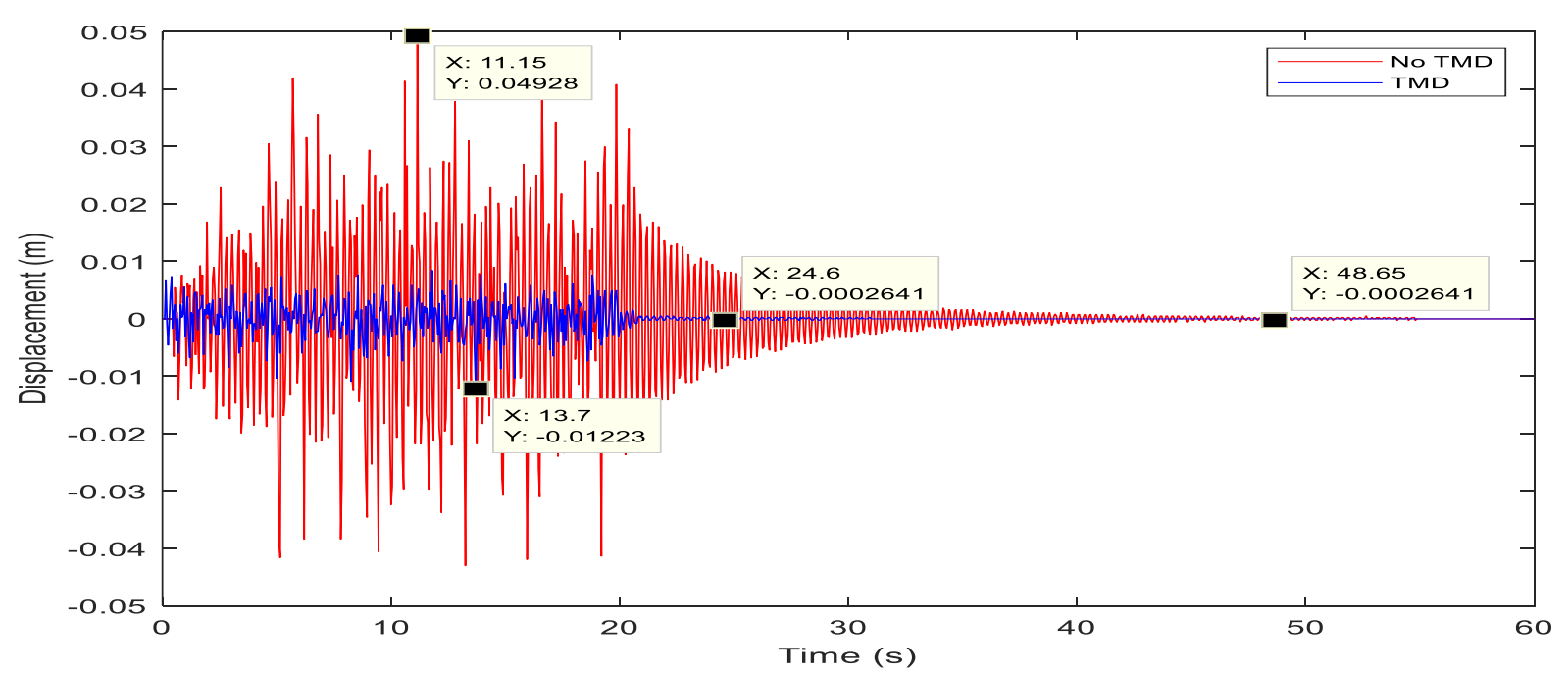

GAMBAR 5. Grafik Perbandingan Respons Struktur Tanpa TMD dan Dengan Penambahan TMD Rasio md 12\% dan kd 10\% Dengan Gaya Gangguan 11,5 rad/s 
Nilai amplitudo yang didapatkan pada struktur dengan penambahan TMD dengan rasio md $12 \%$ dan $\mathrm{kd} 10 \%$ yaitu sebesar $0,0122 \mathrm{~m}$ dan struktur berhenti berosilasi setelah mengalami peluruhan pada 24,6 s. Nilai amplitudo ini mengalami penurunan sebesar $75,19 \%$ dari nilai amplitudo pada struktur tanpa TMD. Hal ini membuktikan bahwa penambahan TMD pada struktur dengan komposisi rasio TMD yang tepat sangat efektif untuk mengurangi amplitudo yang terjadi pada struktur yang berosilasi. Hal ini dikarenakan TMD berhasil mengubah karakteristik dari struktur dan mentransfer energi dari gaya gangguan menuju TMD itu sendiri.

Dalam penelitian ini terdapat 300 data pengujian dengan variasi nilai rasio dari TMD dan gaya gangguan yang diberikan. Masingmasing variasi gaya gangguan memiliki 100 data simpangan terbesar atau amplitudo yang terjadi pada struktur. Nilai amplitudo pada setiap variasi rasio TMD dengan gaya gangguan $10,5 \mathrm{rad} / \mathrm{s}, 11 \mathrm{rad} / \mathrm{s}$, dan $11,5 \mathrm{rad} / \mathrm{s}$ dapat dilihat pada Gambar 6, Gambar 7, dan Gambar 8 .

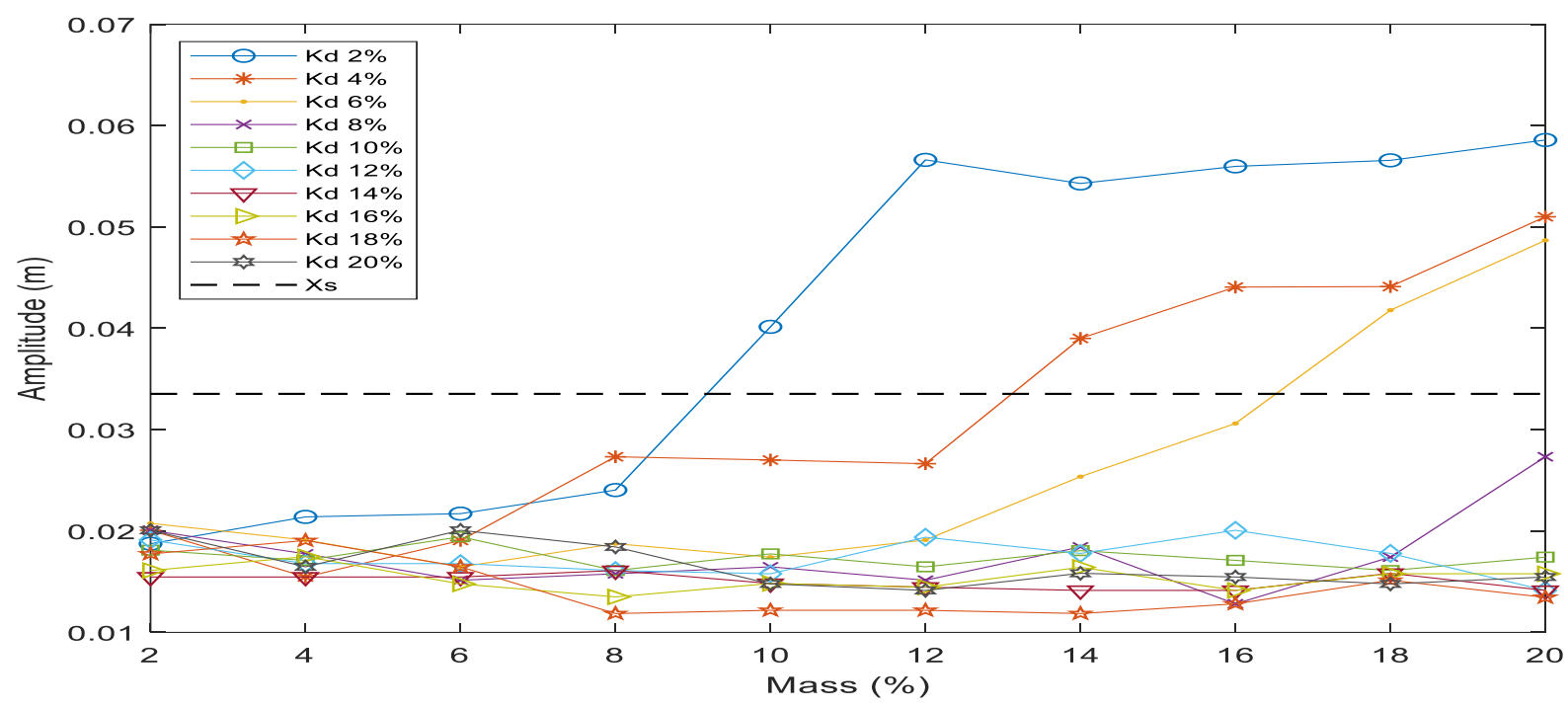

GAMBAR 6. Grafik Nilai Amplitudo Struktur Dengan Penambahan TMD dan Gaya Gangguan 10,5 rad/s

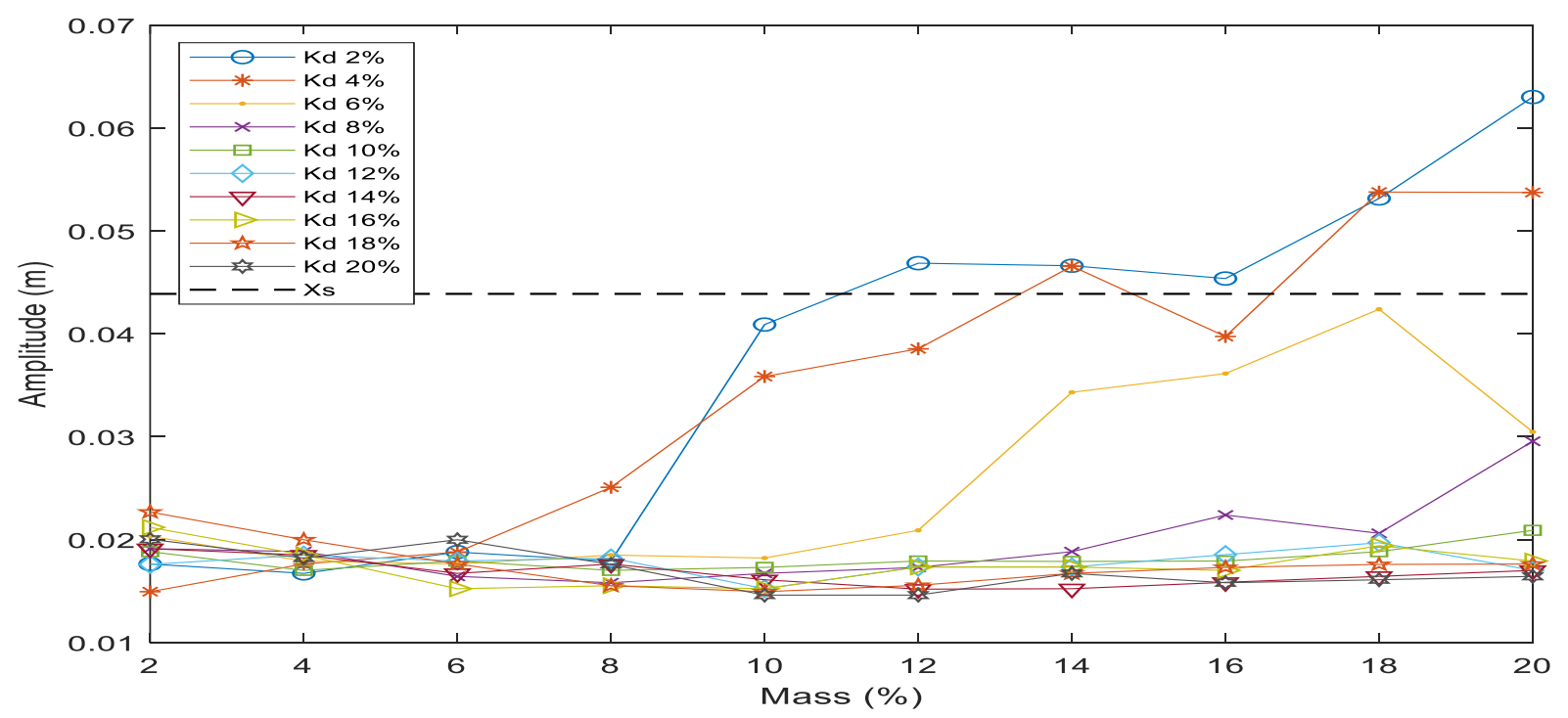

GAMBAR 7. Grafik Nilai Amplitudo Struktur Dengan Penambahan TMD dan Gaya Gangguan $11 \mathrm{rad} / \mathrm{s}$ 


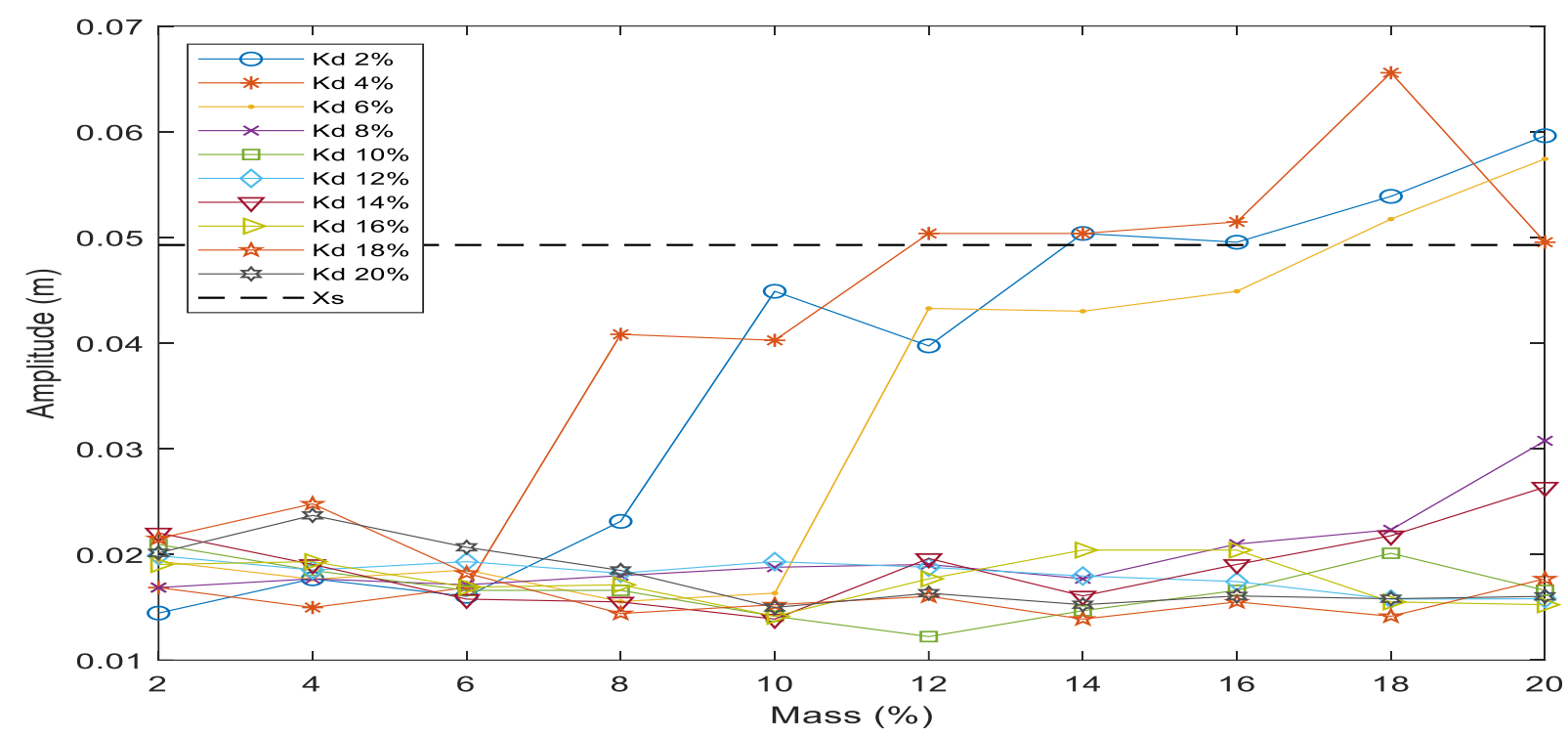

GAMBAR 8. Grafik Nilai Amplitudo Struktur Dengan Penambahan TMD dan Gaya Gangguan 11,5 rad/s

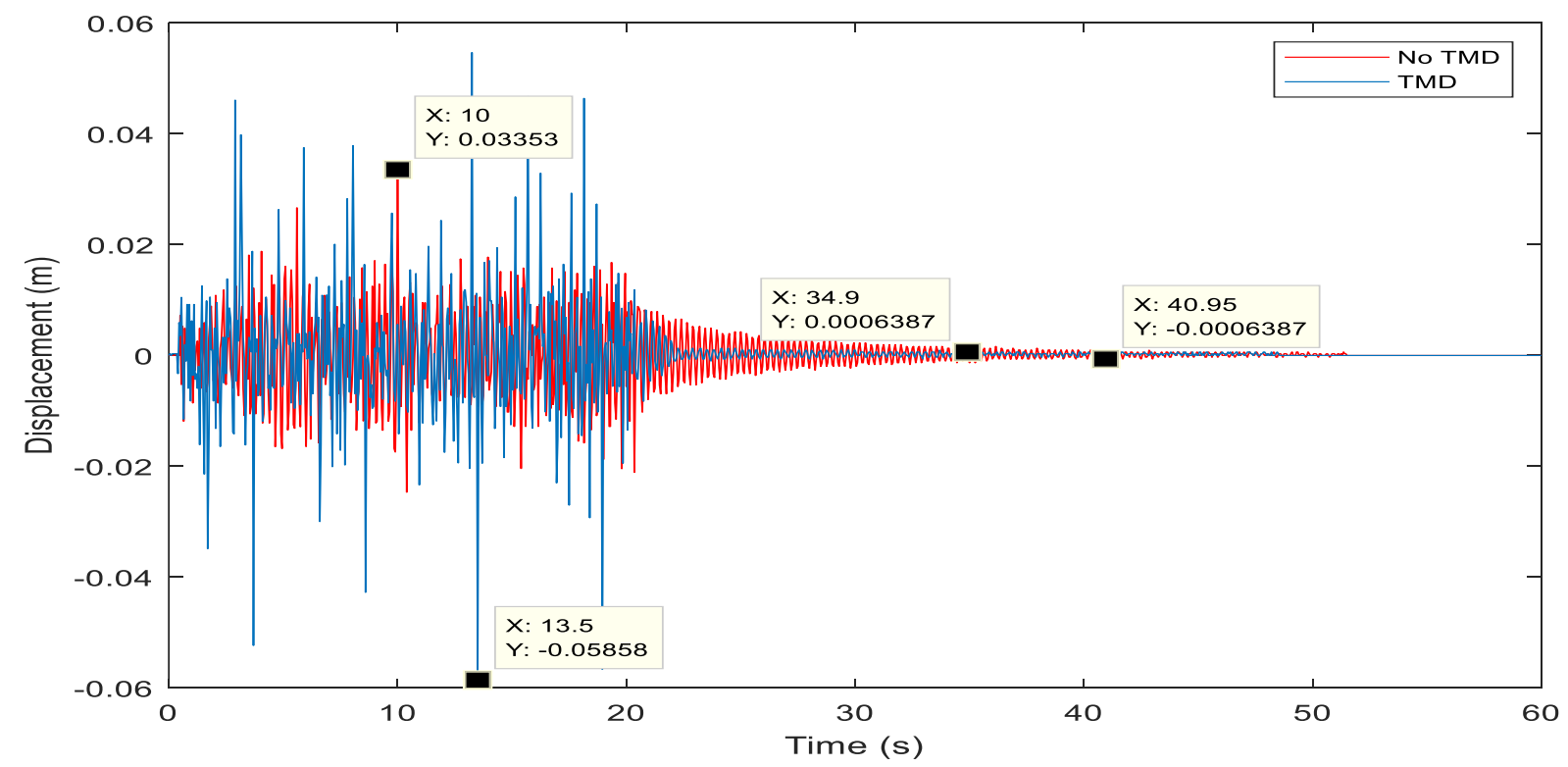

GAMBAR 9. Grafik Perbandingan Respons Struktur Tanpa TMD dan Dengan Penambahan TMD Rasio md 20\% dan kd 2\% Dengan Gaya Gangguan 10,5 rad/s

Gambar 6, 7, dan 8 menyajikan nilai simpangan tertinggi yang terjadi pada struktur dengan penambahan TMD pada masingmasing variasi nilai rasio TMD. Secara umum, amplitudo yang dihasilkan pada setiap variasi rasionya masih bersifat fluktuatif, hal ini terjadi karena gaya gangguan yang diberikan pada struktur masih berada pada titik menuju frekuensi pribadi struktur itu sendiri. Sehingga masih belum membentuk kestabilan dan perkirakan amplitudo akan terus naik jika frekuensi gaya gangguan yang diberikan lebih tinggi sampai menuju nilai frekuensi pribadi struktur itu sendiri dan terjadi fenomena resonansi. Hal ini dibuktikan dengan perbandingan grafik nilai amplitudo terhadap variasi nilai rasio TMD pada Gambar 6, 7, dan 8. Semakin besar frekuensi gaya gangguan yang diberikan pada struktur, maka amplitudo yang dihasilkan akan semakin besar juga pada setiap variasi nilai rasio TMD-nya. 
Untuk memudahkan dalam penyajian data, pada Gambar 6, 7 dan 8 dibagi menjadi dua zona yang dibatasi oleh nilai amplitudo struktur tanpa TMD yang dilambangkan dengan Xs. Zona hijau menandakan bahwa rasio TMD tersebut berada pada zona aman karena rasio tersebut dapat mengurangi respons simpangan pada struktur. Nilai rasio terbaik yang dapat mengurangi respons amplitudo struktur pada gaya gangguan 10,5 $\mathrm{rad} / \mathrm{s}, 11 \mathrm{rad} / \mathrm{s}$, dan 11,5 rad/s berturut-turut yaitu md $8 \% \mathrm{kd} 18 \%$ dengan amplitudo sebesar $0,0118 \mathrm{~m}$ dan mereduksi sebesar $64,62 \%$, md $10 \%$ kd 20\% dengan amplitudo sebesar 0,0146 $\mathrm{m}$ dan mereduksi sebesar $66,69 \%$, serta md $12 \%$ kd $10 \%$ dengan amplitudo sebesar $0,0122 \mathrm{~m}$ dan mereduksi sebesar 75,19\% dari nilai amplitudo struktur tanpa TMD. Zona merah menandakan bahwa rasio TMD tersebut berada pada zona bahaya, kerana rasio tersebut menambah respons simpangan pada struktur yang dapat dilihat pada Gambar 9.

Nilai amplitudo yang didapatkan pada struktur dengan penambahan TMD rasio md 20\% dan $\mathrm{kd} 2 \%$ dengan gaya gangguan $10.5 \mathrm{rad} / \mathrm{s}$ yaitu sebesar $0,0585 \mathrm{~m}$ dan struktur berhenti berosilasi setelah mengalami peluruhan pada 34,9 s. Nilai amplitudo ini mengalami kenaikan sebesar 74,69 \% dari nilai amplitudo pada struktur tanpa TMD yang memiliki amplitudo hanya sebesar $0,0335 \mathrm{~m}$ dan struktur berhenti berosilasi setelah mengalami peluruhan pada 40,95 s. Hal ini dikarenakan nilai kekakuan TMD yang kecil dikombinasikan dengan nilai massa TMD yang besar. Sehingga saat struktur berosilasi, TMD justru memberi gaya dorong pada struktur yang menyebabkan nilai amplitudo yang semakin besar. Bahkan pada saat pengujian TMD membentur atap dari struktur karena kekakuan TMD yang sangat kecil tidak mampu untuk menahan gerakan dari massa TMD yang besar. TMD yang diharapkan dapat mengurangi amplitudo struktur, justru menambah amplitudo yang dihasilkan jika rasio dari TMD yang dipilih tidak tepat, sehingga penelitian ini membagi rasio TMD pada zona aman dan zona bahaya.

\section{KESIMPULAN}

Dari hasil pengujian penerapan sistem peredam jenis Tuned Mass Damper (TMD) pada model struktur dapat disimpulkan bahwa penambahan TMD dapat mereduksi respons simpangan struktur. Nilai rasio TMD sebesar $12 \%$ md dan $10 \% \mathrm{kd}$ merupakan nilai optimum yang dapat mereduksi getaran pada struktur sebesar $75,19 \%$ dibandingkan dengan respons struktur tanpa TMD untuk gangguan 11,5 rad/s.

\section{UCAPAN TERIMA KASIH}

Ucapan terima kasih disampaikan kepada Lembaga Penelitian dan Pengabdian Masyarakat (LPPM) Universitas Bengkulu yang telah mendanai penelitian ini melalui Hibah Penelitian Unggulan UNIB 2020 dengan No. Kontrak 2010/UN30.15/PG/2020 tanggal 23 Juni 2020.

\section{DAFTAR PUSTAKA}

Aghlara, R., Tahir, M. Md., \& Adnan, A. (2018). Experimental study of pipe-fuse damper for passive energy dissipation in structures. Journal of Constructional Steel Research, 148, 351-360. https://doi.org/10.1016/j.jcsr.2018.06.00 4

Chang, C. M., Shia, S., \& Lai, Y. A. (2018). Seismic design of passive tuned mass damper parameters using active control algorithm. Journal of Sound and Vibration, $\quad 426, \quad 150-165$. https://doi.org/10.1016/j.jsv.2018.04.017

Gerges, R. R., \& Vickery B. J. (2005). Optimum design of pendulum-type tuned mass dampers. Structural Design of Tall and Special Buildings, 14(4), 353-368. https://doi.org/10.1002/tal.273

Gorini, D. N., \& Chisari, C. (2019). Effect of soil-structure interaction on seismic performance of tuned mass dampers in buildings. Earthquake Geotechnical Engineering for Protection and Development of Environment and Constructions - Silvestri \& Moraci (Eds). ISBN 978-0-367-14328-2. 
Hart, G. C., Brandow, G. E., Brugger, L., Carpenter, L. D., Quadri, N. D., Huang, S. C., Kashefi, I., Kumabe, C., \& Lew, M. (2012). An alternative procedure for seismic evaluation and strengthening of tall buildings. Structural Design of Tall and Special Buildings, 21. https://doi.org/10.1002/tal.1063

Hebbar, S., Kulal, S. D., Pasha, T., Samal, P. K., \& Gourav, K. (2019). Numerical and experimental investigation of vibration isolation of three-storied building structure using tuned mass damper. International Journal of Recent Technology and Engineering (IJRTE). 8.

Kareem, A., Kijewsky, T., \& Tamura, Y. (1999). Mitigation of motions of tall buildings with specific examples of recent applications. Wind and Structures, 2(3), 201-251.

Liu, Y., Wang, K., Merchan, O., Chen, H., \& Tan, P. (2020). Experimental and numerical studies on the optimal design of tuned mass dampers for vibration control of high-rise structures. Engineering Structures, 211, 110486. https://doi.org/10.1016/j.engstruct.2020. 110486

Liu, C., Gao, R., \& Guo, B., (2018). Seismic design method analyses of an innovative steel damping bearing for railway bridges. Engineering Structures, 167, 518-532.

https://doi.org/10.1016/j.engstruct.2018. 04.076

Mendis, P., Ngo, T., Haritos, N., Hira, A., Samali, B., \& Cheung, J. (2007) Wind loading on tall buildings. EJSE Special Issue: Loading on Structures (2007).

Sikumbang, A. B. (2014). Analisis Efektifitas Penempatan Tuned Mass Damper Pada Bangunan Bertingkat Dalam Mereduksi Respon Struktur Akibat Beban Gempa. Departemen Teknik Sipil Universitas Sumatera Utara.

Suryadi, D. dkk (2019). Pemodelan sistem peredam (tuned mass damper) pada struktur menggunakan Matlab Simulink. Prosiding dari Seminar Nasonal Inovasi, Teknologi dan Aplikasi (SeNITiA). Bengkulu, Indonesia: Universitas Bengkulu.
Tjong, W. F., Andriono, T., Sumendap, R., \& Gunawan, F. (2004). Studi efektifitas penggunaan tuned mass damper pada struktur gedung dalam mereduksi respons dinamik akibat beban seismik. Dimensi Teknik Sipil 5(2), 51-62.

PENULIS:

Dedi Suryadi

Program Studi Teknik Mesin, Fakultas Teknik, Universitas Bengkulu. Jalan WR. Supratman, Kandang Limun, Bengkulu.

Email: dedi_suryadi@unib.ac.id

\section{Rasyid Ridlo}

Program Studi Teknik Mesin, Fakultas Teknik, Universitas Bengkulu. Jalan WR. Supratman, Kandang Limun, Bengkulu.

Email: mrasyid_ridlo@gmail.com

Novalio Daratha

Program Studi Teknik Elektro, Fakultas Teknik, Universitas Bengkulu. Jalan WR. Supratman, Kandang Limun, Bengkulu.

Email: ndaratha@unib.ac.id

Indra Agustian

Program Studi Teknik Elektro, Fakultas Teknik, Universitas Bengkulu. Jalan WR. Supratman, Kandang Limun, Bengkulu.

Email: iagustian@unib.ac.id 